\title{
Indoor temperature conditions and energy demand of a Finnish detached house in a changing climate
}

\author{
Azin Velashjerdi Farahani ${ }^{{ }^{*}}$, Juha Jokisalo ${ }^{1,3}$, Natalia Korhonen ${ }^{2}$, and Risto Kosonen ${ }^{1,3,4}$ \\ ${ }^{1}$ Department of Mechanical Engineering, Aalto University, Espoo, Finland \\ ${ }^{2}$ Weather and Climate Change Impact Research, Finnish Meteorological Institute, Helsinki, Finland \\ ${ }^{3}$ Smart City Center of Excellence, TalTech, Tallinn, Estonia \\ ${ }^{4}$ College of Urban Construction, Nanjing Tech University, Nanjing, China
}

\begin{abstract}
This study investigated the effect of passive strategies (orientation, thermal mass of building structure, window opening, and window properties) and the usage of an active cooling system on energy demand and indoor temperature conditions of a detached house in Finland in the current (TRY 2012) and future climatic conditions (2050). So that nine different cases were defined and simulated. The goal was to improve the indoor temperature conditions in the cooling season and analyze the effects of global warming on energy demand. Regarding the results of passive strategies, in the current climate, using openable windows would be the best solution for decreasing the cooling demand and providing acceptable indoor air temperature of the spaces. In this case, $96 \%$ of the time in the cooling season, the indoor temperature is below the maximum recommended indoor temperature $\left(27^{\circ} \mathrm{C}\right)$ of the thermal environment category III of the standard EN 15251 and EN 16798-1. While using an active cooling system in the hall of the upper floor, it is the only studied solution that can provide thermal comfort in all the spaces during the cooling season in both current and future climate based on the standards. In the future 2050 climate, the heating demand decreases much more than the amount of increase in the cooling demand. So that the total electricity demand of electrically heated detached houses in the future climate would be less than in the current climate.
\end{abstract}

\section{Introduction}

Climate change is mostly about the gradual increase in ambient temperature. Northern areas will experience this warming up the most in addition to some frequent heatwaves [1]. Increasing temperatures cause adverse effects on health (e.g., increased infant mortality and lower life expectancy) both in the short and long run [2]. Providing comfort in indoor temperature conditions, global warming leads to a reduction in heating demands and a corresponding increase in cooling demands [3].

This study is part of a project entitled HeatClim which is focused on the effects of future climate on e.g. thermal comfort and energy demand and is funded by the Academy of Finland.

In this paper, we aim to investigate the effects of passive strategies (orientation, thermal mass of the structure, window opening, and glass properties) and the usage of an active cooling system on energy demand and indoor temperature conditions of a detached house in Finland, in a changing climate using simulation. The case study, simulation tools and cases, and weather files are defined in the Methods. The results are compared and discussed in the Results and Discussion.

\section{Methods}

\subsection{Case study}

The example building of this study is a new 2-story detached house which locates in Helsinki. The heated net floor area of the house is $180 \mathrm{~m}^{2}$, and the geometry and properties of the example building, and its orientation is described in Fig. 1.

It is assumed that the example building is in a neighborhood where similar buildings surround it. The height of the surrounding buildings is as same as the example building. The neighborhood is shown in Fig. 2.

The properties of the building envelope are as described in Table 1. The thermal insulation level of the building is high corresponding to the Finnish guidelines for Finnish Passive houses [4] and the type of building structure is massive.

Space heating of the building is carried out with electric radiators. Electric radiators which dimensioning heating power is $5 \mathrm{~kW}\left(28 \mathrm{~W} / \mathrm{m}^{2}\right)$ at dimensioning outdoor temperature $\left(-26^{\circ} \mathrm{C}\right)$ of southern Finland. The temperature setpoint of space heating is $21^{\circ} \mathrm{C}$. There is no mechanical cooling in the building in the base case.

\footnotetext{
* Corresponding author: azin.velashjerdifarahani@aalto.fi
} 

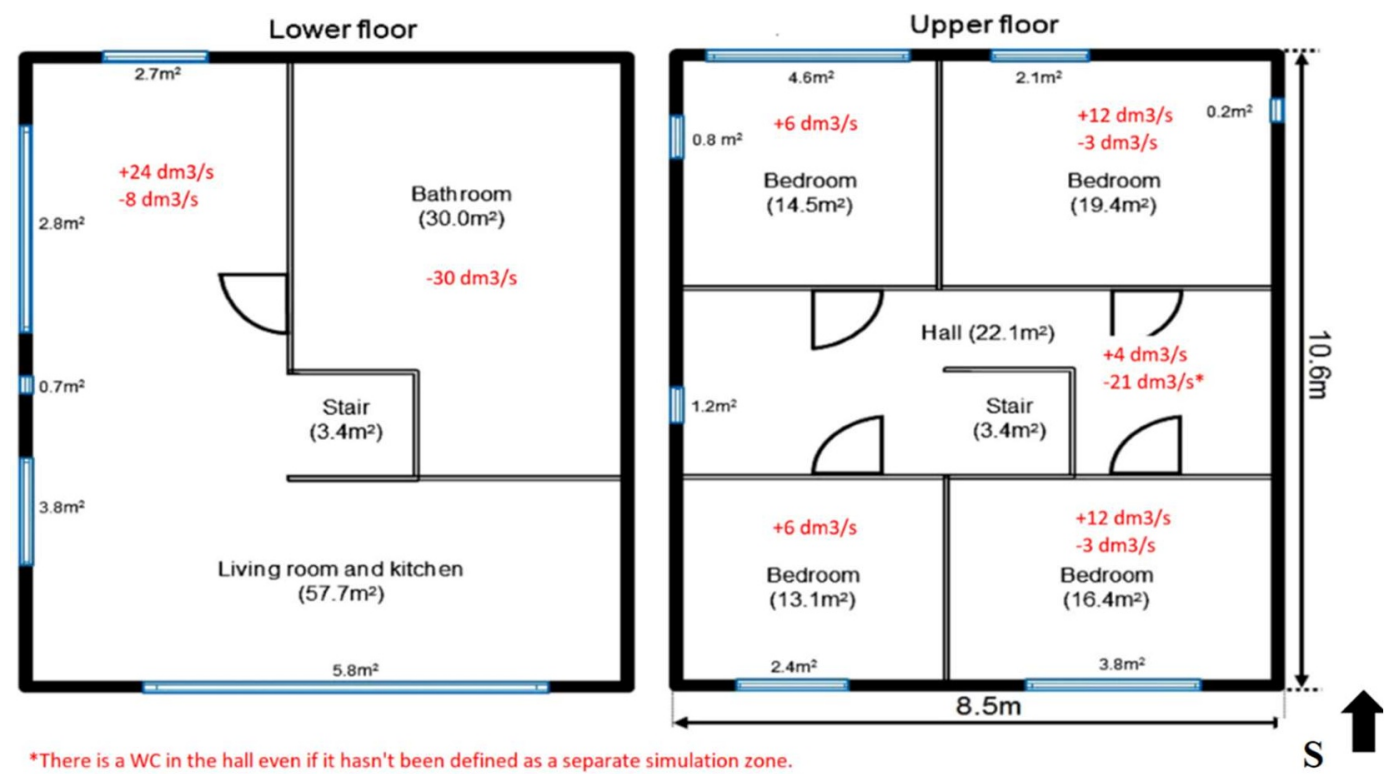

Figure 1. The geometry of the example building.

The ventilation system is a balanced ventilation system with heat recovery and the setpoint temperature of supply air heating is constant $17{ }^{\circ} \mathrm{C}$, and the air handling unit (AHU) doesn't have mechanical cooling. The AHU is equipped with an electric reheat coil, which is used for heating the supply air. Also, the airflow rates in different rooms are shown in Fig. 1. Positive values are the supply airflow rates and the negative ones the exhaust airflow rates. The total air exchange rate of the building is $0.5 \mathrm{ACH}$, and $\mathrm{q}_{50}$ is $0.7 \mathrm{~m}^{3} / \mathrm{h}, \mathrm{m}^{2}$.

There is an integrated shading for all the windows, blinds between panes are used when the intensity of solar radiation on the windows exceeds $100 \mathrm{~W} / \mathrm{m}^{2}$.

The usage of the building and internal heat gains are as follows:

Occupants: Four occupants (two adults and children). During the daytime, the adults are working outside the house every weekday, and the children are at school. The activity and clothing levels are 1.2 Met and 0.96 Clo. The parents sleep in the master bedroom (16.4 $\mathrm{m}^{2}$ ), and the children sleep in the two smallest bedrooms. The bedroom of $16.4 \mathrm{~m}^{2}$ is used as a working and hobby room.

Household appliances: Total annual electricity consumption is $22.8 \mathrm{kWh} / \mathrm{m}^{2}$ [5]. The electric power of the appliances is evenly distributed by the floor area of the living spaces, and the appliances are used every day between 7:00-23:00 according to the occupancy profiles. There are additional household devices in the bathroom, $50 \mathrm{~W}$ constant power which is always on, which simulates heat gains from a DHW storage tank, and in the living room, $150 \mathrm{~W}$ constant power which is always on, which simulates heat gains from a fridge, freezer and consumer electronics (standby consumption).

Indoor lighting: Total annual electricity consumption is $8.4 \mathrm{kWh} / \mathrm{m}^{2}$ [5]. The electric lighting power $\left(\mathrm{W} / \mathrm{m}^{2}\right)$ is evenly distributed by the floor area of the living spaces and the usage time of the lights are:
- $\quad 1.5$ - 31.8: between 21:00-23:00

- $\quad 1.9-30.4$ : between $6: 30-9: 00$ and 15:0023:00

The internal door of the bathroom is always closed, but other internal doors are always open. There is a $2 \mathrm{~cm}$ high gap between the bathroom door and the floor.

The annual net heating demand for domestic hot water (DHW) is $35 \mathrm{kWh} / \mathrm{m}^{2}$ [6]. Distribution losses of DHW are $0.5 \mathrm{~W} / \mathrm{m}^{2}$ (floor area), and it can be assumed that $50 \%$ of the losses end up with internal heat gains. It was assumed that DHW is consumed regularly every day between 7:00-9:00 and 15:00-23:00.

\subsection{Climatic data and simulation tool}

The simulation period of the cases is one year, and the weather data of the study is TRY (2012) of HelsinkiVantaa, which describes the current climatic conditions of southern Finland [7]. Also, two of the cases are simulated using projected weather data of the year 2050 (TRY 2050) of Helsinki-Vantaa with A2 GHG emission scenario [8]. Fig. 3 shows the outdoor temperature duration curves in 2012 and 2050. In 2050, the maximum outdoor temperature is about $30{ }^{\circ} \mathrm{C}$, and in 2012 , it is $28.8^{\circ} \mathrm{C}$. The minimum outdoor temperature is $-15.5^{\circ} \mathrm{C}$ and $-20.6{ }^{\circ} \mathrm{C}$ in 2050 and 2012 , respectively. Fig. 3 reveals that the outdoor temperatures in winter are projected to increase more than in summer. The average outdoor temperature of three summer months (June, July, and August) is $15.9{ }^{\circ} \mathrm{C}$ in 2012 and is $17.4{ }^{\circ} \mathrm{C}$ in 2050. The annual average outdoor temperature is $5.6^{\circ} \mathrm{C}$ and $7.7{ }^{\circ} \mathrm{C}$ in 2012 and 2050, respectively. Solar radiation doesn't change significantly $(-5 \%$ in winter and $+5 \%$ in summer) in these two test reference year climatic data.

The time step of the simulation results is 1 hour. The simulation is done using the validated dynamic building simulation tool IDA ICE 4.8. 


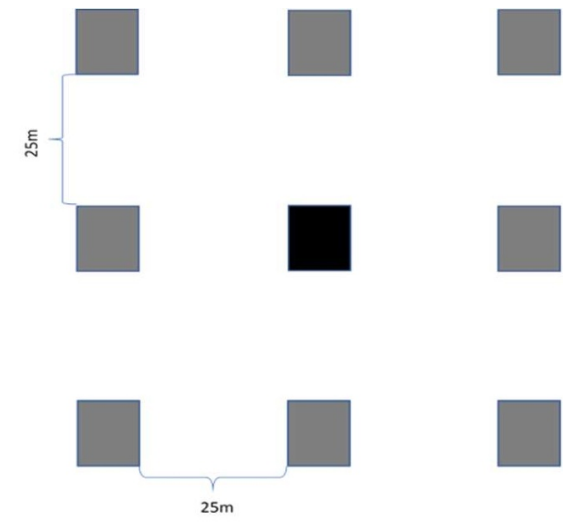

Figure 2. The location of the simulated example building (black box) and the surrounding buildings (grey boxes).

\subsection{Simulation cases}

The nine different cases are defined to investigate the effects of some passive cooling strategies and an active one on energy demand and indoor air temperature conditions. Except for Case 1, others can be categorized into three main groups. The first one investigates passive strategies; in the second one, an active cooling system is used. In the third one, the future weather file is used.

Case 1 is a reference case without mechanical cooling and openable windows. Properties of the building and HVAC system are as described previously.

- Group 1, Passive strategies:

Case 2 is similar to Case 1, but the orientation of the building is changed $180^{\circ}$.

Case 3 is similar to Case 1 , but the building is equipped with solar protection windows, which U-value is similar to Case 1. Still, the total solar heat transmittance (g-value) of the windows is 0.19 , and the direct solar transmittance (ST-value) is 0.16 .

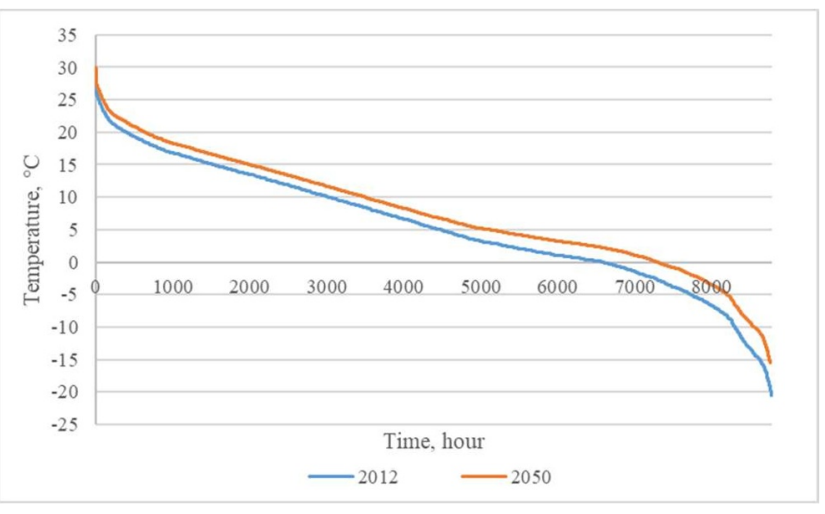

Figure 3. The temperature duration curves 2012, 2050.

Case 4 is similar to Case 1, but $10 \%$ of the largest window of the rooms is open during the occupied hours if the indoor temperature of the rooms exceeds $25^{\circ} \mathrm{C}$.

Case 6 is similar to Case 1, but it is simulated using the lightweight (LW) structures of the building defined in Table 2.

- Group 2, Active cooling system:

Case 5 is similar to Case 1 , but the hall of the upper floor is equipped with a split cooling unit of $4.6 \mathrm{~kW}$ $\left(25.5 \mathrm{~W} / \mathrm{m}^{2}\right.$ per net floor area) cooling capacity and SCOP of 3 . The temperature setpoint of space cooling is $23^{\circ} \mathrm{C}$ because it is located in the upper floor corridor ( category II of the standard EN 15251 and EN 16798-1). [9] [10].

Case 7 is similar to Case 5, but it is simulated using the lightweight (LW) structures of the building defined in Table 2.

- Group 3, Future climate:

Case 8 is similar to Case 1 , but it is simulated using TRY 2050.

Case 9 is similar to Case 5, but it is simulated using TRY 2050.

Table 1. The case building's envelop properties, Massive structure.

\begin{tabular}{|c|c|c|c|}
\hline $\begin{array}{l}\text { Elements of } \\
\text { construction }\end{array}$ & Properties & Thickness (mm) & $\begin{array}{c}\text { U value } \\
\left(\mathbf{W} / \mathbf{m}^{2} \mathbf{K}\right)\end{array}$ \\
\hline External wall & $\begin{array}{l}\text { Light weight concrete block }(130 \mathrm{~mm}) \text {, polyurethane }(340 \mathrm{~mm}) \text {, } \\
\text { light weight concrete block }(90 \mathrm{~mm})\end{array}$ & 560 & 0.08 \\
\hline Internal wall & Lightweight concrete block (100mm) & 100 & - \\
\hline Roof & $\begin{array}{c}\text { Filler }(5 \mathrm{~mm}) \text {, concrete }(100 \mathrm{~mm}), \text { mineral wool }(490 \mathrm{~mm}) \text {, } \\
\text { waterproof sheet }(10 \mathrm{~mm})\end{array}$ & 605 & 0.07 \\
\hline Base floor & $\begin{array}{l}\text { Wood }(14 \mathrm{~mm}) \text {, light weight concrete }(15 \mathrm{~mm}) \text {, concrete }(100 \mathrm{~mm}) \text {, } \\
\text { EPS thermal insulation }(480 \mathrm{~mm})\end{array}$ & 609 & 0.08 \\
\hline Intermediate floor & $\begin{array}{l}\text { Wood }(15 \mathrm{~mm}) \text {, light weight concrete }(15 \mathrm{~mm}) \text {, concrete }(100 \mathrm{~mm}) \text {, } \\
\qquad \text { filler }(5 \mathrm{~mm})\end{array}$ & 135 & - \\
\hline Window & $\begin{array}{l}\text { Total solar heat transmittance }(\mathrm{g})=0.5 \\
\text { Direct solar transmittance }(\mathrm{ST})=0.4\end{array}$ & - & 0.8 \\
\hline
\end{tabular}


Table 2. The example building's envelop properties, Lightweight structure.

\begin{tabular}{|c|c|c|c|}
\hline $\begin{array}{l}\text { Elements of } \\
\text { construction }\end{array}$ & Properties & Thickness (mm) & $\begin{array}{c}\text { U value } \\
\left(\mathbf{W} / \mathbf{m}^{2} \mathbf{K}\right)\end{array}$ \\
\hline External wall & $\begin{array}{c}\text { Gypsum }(13 \mathrm{~mm}) \text {, wooden frame }(150 \mathrm{~mm})+\text { mineral wool } \\
\text { (390 mm), wind shield board }(9 \mathrm{~mm})\end{array}$ & 557 & 0.08 \\
\hline Internal wall & Gypsum (13 mm), wooden frame $(40 \mathrm{~mm})$, gypsum $(13 \mathrm{~mm})$ & 66 & - \\
\hline Roof & $\begin{array}{l}\text { Gypsum }(13 \mathrm{~mm}), \text { wooden frame }(150 \mathrm{~mm})+\text { mineral wool } \\
\qquad(460 \mathrm{~mm}) \text {, water proof sheet }(10 \mathrm{~mm})\end{array}$ & 633 & 0.07 \\
\hline Base floor & $\begin{array}{l}\text { Wood }(14 \mathrm{~mm}) \text {, wooden frame }(200 \mathrm{~mm})+\text { mineral wool }(335 \\
\mathrm{mm}) \text {, windshield board }(9 \mathrm{~mm})\end{array}$ & 558 & 0.08 \\
\hline Intermediate floor & $\begin{array}{l}\text { Wood (15 mm), particleboard (22 mm), wooden frame (150 } \\
\qquad \mathrm{mm}) \text {, gypsum }(13 \mathrm{~mm})\end{array}$ & 200 & - \\
\hline Window & $\begin{array}{l}\text { Total solar heat transmittance }(\mathrm{g})=0.5 \\
\text { Direct solar transmittance }(\mathrm{ST})=0.4\end{array}$ & - & 0.8 \\
\hline
\end{tabular}

\section{Results and discussion}

The results are presented in two different parts, the first one, annual electricity consumption, which is compared in different cases. The second one is an assessment of the indoor air temperature in the warmest bedroom with $14.5 \mathrm{~m}^{2}$ area (Fig.1), to find out the effects of the measures in each case on indoor conditions. analysing the indoor air temperature, is based on EN 15251 and EN 16798-1; the European standard specifies the indoor environmental parameters, which have an impact on the energy performance of the buildings. Table 3 shows recommended range of indoor temperatures for the cooling season for three categories I-III of the thermal environment [9] [10].

Table 3. Temperature range for different categories based on EN 15251 and EN 16798-1.

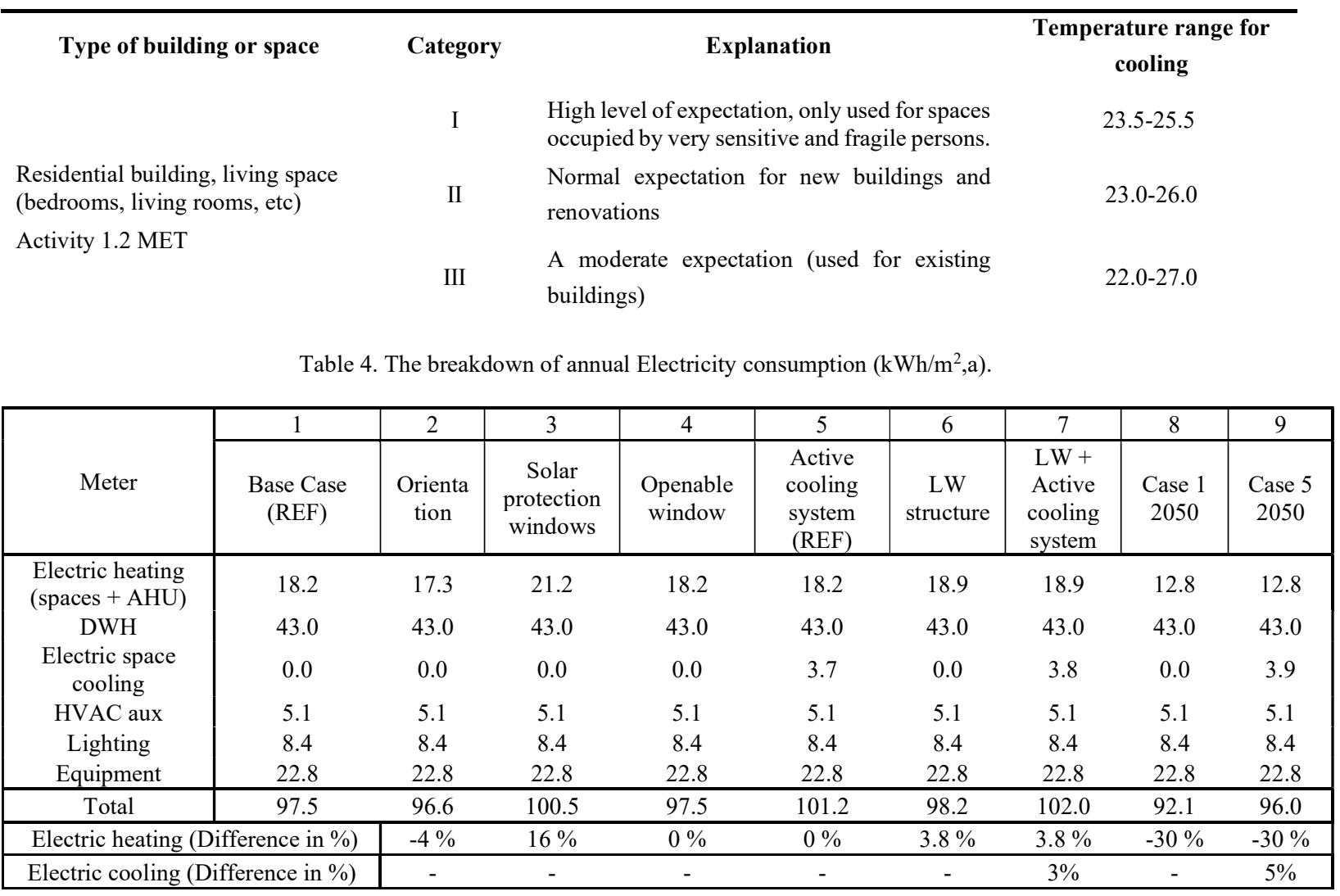




\subsection{The breakdown of annual electricity consumption}

Firstly, it is essential to compare the results of Case 1 to other cases. Thus, Table 4 is a summary of the breakdown of the annual electricity consumption of the nine cases.

As it is reported in Table 4, the heating demand in cases 8 and 9 which are simulated using the future weather data, is the lowest by $12.8 \mathrm{kWh} / \mathrm{m}^{2}$, a, which has decreased by $5.4 \mathrm{kWh} / \mathrm{m}^{2}$, a (30\%) compared to the base case, due to global warming.

In Case 2, because of the large windows facing south, the heating demand is less than in Case 1 by 0.9 $\mathrm{kWh} / \mathrm{m}^{2}$. The usage of solar protection windows causes an increase of $3 \mathrm{kWh} / \mathrm{m}^{2}$,a $(16 \%)$ in heating demand in Case 3. Cases 6 and 7 have slightly higher heating demand by $0.7 \mathrm{kWh} / \mathrm{m}^{2}$, a $(3.8 \%)$ due to the light structure and less thermal mass. Case 4 in energy demand is like Case 1, but due to the openable windows, the indoor conditions may be different.

Comparing the cooling demand in cases 5, 7, and 9 reveals that Case 9 has the highest one, which is 0.2 $\mathrm{kWh} / \mathrm{m}^{2}$, a (5\%) higher than Case 5 which shows the effect of global warming. The next highest number is in Case 7 with $3 \%$ increase, because of the lightweight structure. Since the share of annual cooling electricity in the total electricity consumption is quite low, it is not significantly influential on the current and future electricity consumption of the building.

\subsection{The assessment of the indoor air temperature}

\subsubsection{The warmest bedroom}

Some of the strategies do not affect heating demand but can change the indoor temperature in the cooling season. Therefore, analyzing the hourly indoor temperature is necessary. The duration curves are shown in Fig. 4.

Openable windows (Case 4) and solar protection windows (Case 3 ) are the most effective passive strategies on indoor air temperature during the year based on Fig. 4. South-front orientation and lightweight structure are the critical ones in terms of warm hours. The split unit can significantly decrease the temperature in the bedroom even it is in the hall, due to the open doors (Cases 5, 7, and 9).

The percentage of total hours $(5879 \mathrm{~h})$ from March to October) in which the indoor air temperature is higher than the maximum acceptable temperature in each thermal environment category (Table 3 ) is calculated based on EN 15251 and EN 16798-1 in each case, and the results are shown in Fig. 5. The indoor air temperature of the warmest bedroom in cases 5 and 9 which are with the usage of an active cooling system, doesn't exceed the maximum recommended temperature in all the categories. Thus, they are the best ones considering thermal comfort in the warmest bedroom. In Case 7, it is slightly higher in categories I and II and the same in category III. Cases 3 and 4 in which the passive solutions are used, with about $20 \%$ and $14 \%$ in category I and II are the next two ones. In category III, it is less than $4 \%$ in Case 4 and around $7 \%$ in Case 3.

To understand the effects of each strategy, the degree hours above $25^{\circ} \mathrm{C}$ in each case is shown in Fig. 6, and the percentage of difference in degree hours above 25

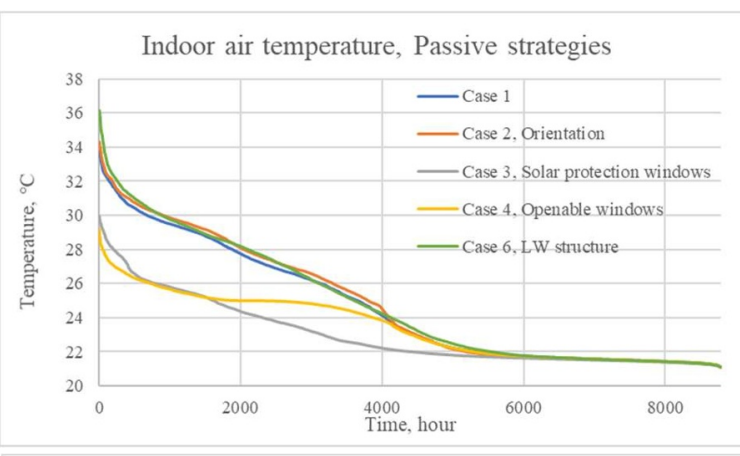

Indoor air temperature, Active cooling system
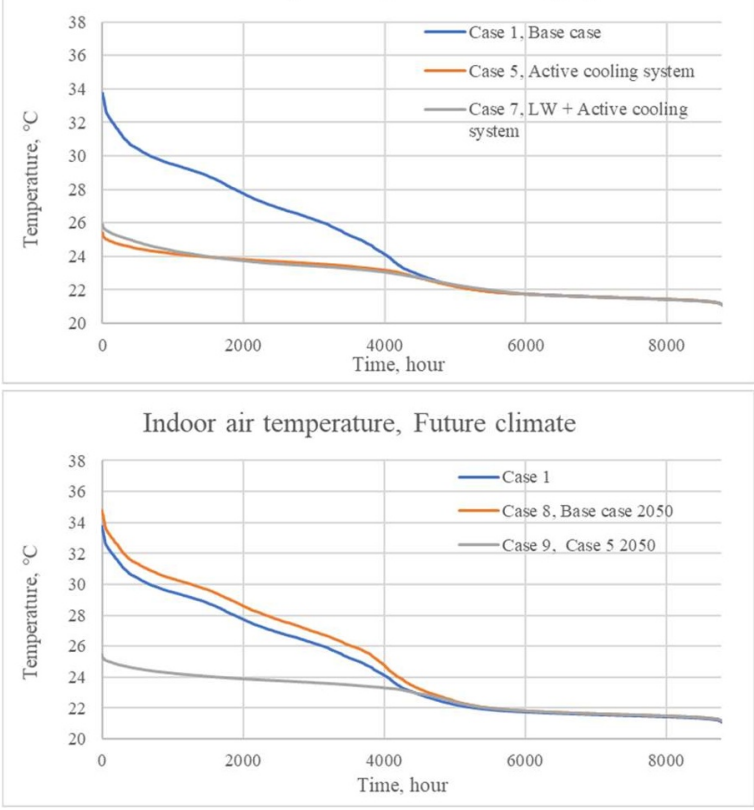

Figure 4. The indoor air temperature duration curves in the warmest bedroom.

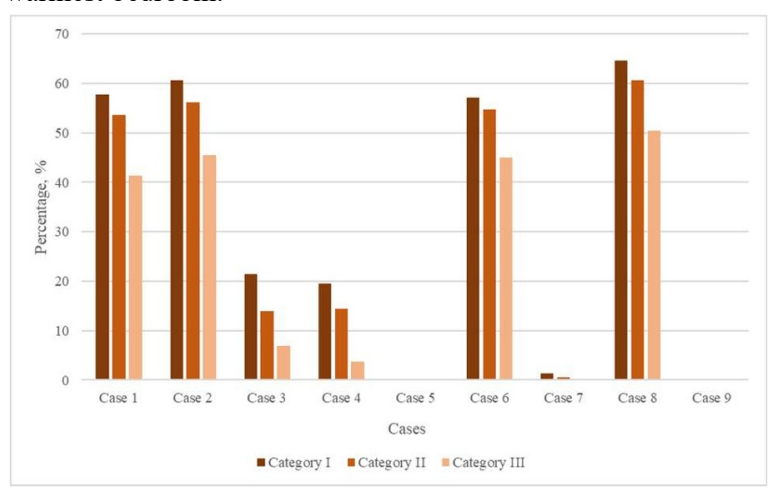

Figure 5. The percentage of hours above the recommended indoor temperature range, from March to October in the warmest bedroom. 


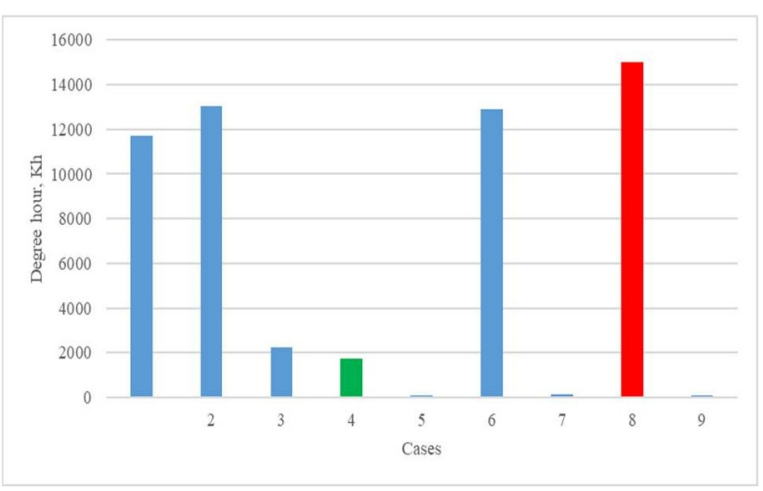

Figure 6. Degree hours above $25^{\circ} \mathrm{C}$ in the warmest bedroom.

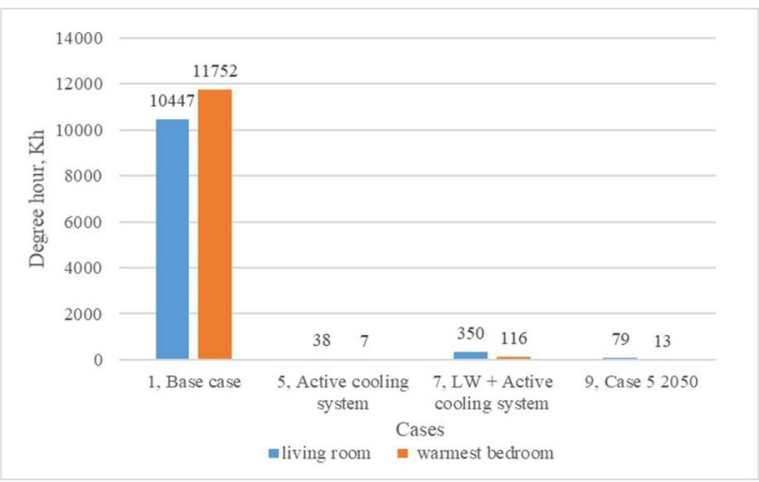

Figure 8 . Degree hours above $25^{\circ} \mathrm{C}$ in the warmest bedroom and the living room.

${ }^{\circ} \mathrm{C}$ in comparison to Case 1 , is calculated and presented in Fig. 7. These charts show that changing orientation and lightweight structure have negative effects on the indoor air temperature. In contrast, the openable windows and solar protection windows have been the most effective ones. Using a cooling system in the hall has improved the indoor condition of the bedroom by decreasing the degree hours above $25^{\circ} \mathrm{C}$, with more than $99 \%$ in both massive and lightweight structure cases.

In the future climate, maintaining acceptable indoor conditions without active cooling will be even more challenging due to global warming. As can be seen in the charts, Case 8 indoor condition is $27.8 \%$ worse than Case 1.

\subsubsection{Living room}

The living room's indoor air temperature is also influenced by the cooling system in the hall. Fig. 8 shows the degree hours above $25^{\circ} \mathrm{C}$ of the living room and the warmest bedroom in cases $1,5,7$, and 9. It is slightly cooler than the warmest bedroom in all cases. The cooling system in Case 5 has reduced the degree hours above $25^{\circ} \mathrm{C}$ by almost $100 \%$ in the living room and bedroom. In Case 7 in which the structure is lightweight and a split cooling unit is used in the hall, the decrease in the bedroom is about $99 \%$, and in the living room is $96 \%$. Thus, the cooling system has been slightly more effective on the bedroom's air temperature. However, the lightweight structure in the current climatic conditions causes more degree hours

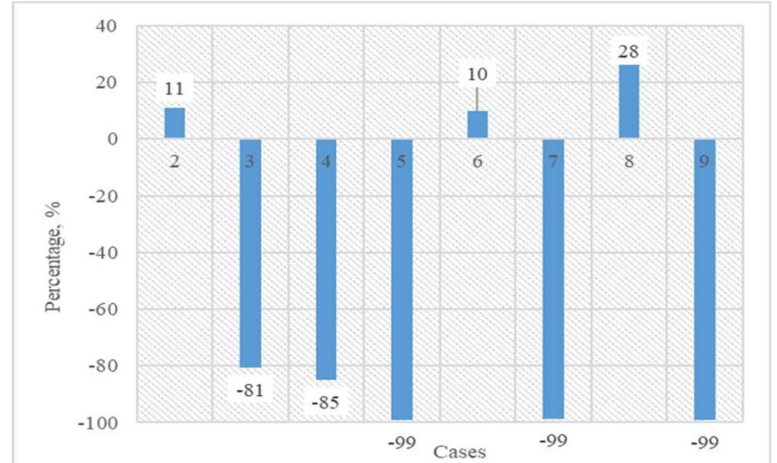

Figure 7. The percentage of difference in degree hours above $25^{\circ} \mathrm{C}$ in comparison to Case 1 in the warmest bedroom.

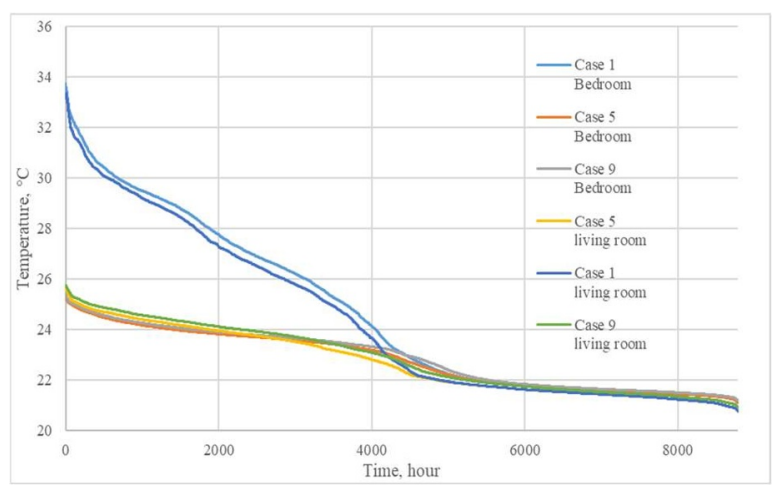

Figure 9. Duration curves of indoor air temperature of the living room and the warmest bedroom, Cases 1 and 5 .

above $25{ }^{\circ} \mathrm{C}$ compared to the massive building in the current (Case 5) or future (Case 9) climatic conditions Furthermore, the effect of the cooling system is shown by the duration curve in Fig. 9. As can be seen, it has improved the condition in both the living room and the bedroom in the current and future climate. So that there is no need to increase the dimensioning power of active cooling in the studied building in the future climate conditions because similar indoor temperature conditions can be achieved by the same dimensioning cooling power $\left(25.5 \mathrm{~W} / \mathrm{m}^{2}\right)$ of the split cooling unit both in the current and future climate conditions.

\section{Conclusions}

This study has investigated the effects of passive strategies, active cooling, and climate change on indoor temperature conditions and the energy demand of a Finnish detached house. Nine different cases were simulated in the cold climate of Finland.

Regarding the results of passive strategies, in the current climate, using openable windows would be the best solution for decreasing the cooling demand, and keeping the indoor air temperature of the spaces in the comfort zone from March to October. It important to note that depending on the location and surrounding of the building, window opening may decrease the indoor air quality and increase the indoor noise level, so the window opening cannot be recommended in such conditions. The lower level of the thermal mass of the building structure causes a slight increase in indoor temperature. 
Because of the open door between the rooms, using an active cooling system in the hall of the upper floor is the only solution that can provide thermal comfort in all the spaces, the whole time of the cooling season in both current and future climate.

Considering the thermal environment categories, by using the openable windows and solar protection windows the indoor air temperature can be maintained in the recommended levels of category III for more than $90 \%$ of the summertime in the current climatic conditions. However, an active cooling system in the upper floor hall can provide the recommended thermal environment for all the spaces, in all the categories, in current and future climate with the massive or lightweight structures.

In the future climate, the heating demand decreases about $30 \%$ which is way more than the amount of increase in the cooling demand by $5 \%$. So that the total electricity demand in the future climate would be less than the current climate by $5 \%$ and using the active cooling systems can provide the acceptable indoor temperature. Also, the indoor conditions would be improved by utilizing passive strategies such as openable windows and solar protection windows.

This study is part of the following projects: HEATCLIM (Heat and health in the changing climate, Grant Numbers. 329306, 329307) funded by the Academy of Finland within the CLIHE (Climate change and health) programme, FINEST Twins funded by European Union (Horizon 2020 programme, Grant No. 856602) and the Estonian government, SUREFIT (Sustainable solutions for affordable retrofit of domestic buildings) funded by European Union (Horizon 2020 programme, Grant No. 894511).

\section{References}

1. S. Russo, J. Sillmann, and E. M. Fischer, "Top ten European heatwaves since 1950 and their occurrence in the coming decades," Environ. Res. Lett., vol. 10, no. 12, 2015, doi: 10.1088/17489326/10/12/124003.

2. D. Meierrieks, "Weather shocks, climate change and human health," World Dev., vol. 138, p. 105228, 2021, doi: 10.1016/j.worlddev.2020.105228.

3. M. A. D. Larsen, S. Petrović, A. M. Radoszynski, R. McKenna, and O. Balyk, "Climate change impacts on trends and extremes in future heating and cooling demands over Europe," Energy Build., vol. 226, 2020, doi: 10.1016/j.enbuild.2020.110397.

4. RIL, "RIL 249-2010

Matalaenergiarakentaminen, Asuinrakennukset (Low energy construction, residential buildings)." Helsinki, 2009.

5. B. Alimohammadisagvand, S. Alam, M. Ali, M. Degefa, J. Jokisalo, and K. Sirén, "Influence of energy demand response actions on thermal comfort and energy cost in electrically heated residential houses," Indoor Built Environ., vol. 26, no. 3 , pp. 298-316, 2017, doi: $10.1177 / 1420326$ X15608514.

6. Ministry of Environment, "Decree (1010/2017) of the Ministry of the Environment on the energy performance of the new building." Helsinki, Finland, 2018.

7. T. Kalamees, K. Jylhä, H. Tietäväinen, J. Jokisalo, S. Ilomets, R. Hyvönen, and S. Saku, "Development of weighting factors for climate variables for selecting the energy reference year according to the en ISO 15927-4 standard," Energy Build., vol. 47, pp. 53-60, 2012, doi: 10.1016/j.enbuild.2011.11.031.

8. K. Jylhä, J. Jokisalo, K. Ruosteenoja, K. PilliSihvola, T. Kalamees, T. Seitola, H. Mäkelä, R. Hyvönen, M. Laapas, and A. Drebs, "Energy demand for the heating and cooling of residential houses in Finland in a changing climate," Energy Build., vol. 99, pp. 104-116, 2015, doi: 10.1016/j.enbuild.2015.04.001.

9. Standard SFS-EN 15251, 'Indoor environmental input parameters for design and assessment of energy performance of buildings addressing indoor air quality, thermal environment, lighting and acoustics', Finnish Standards Association SFS, Helsinki, Finland, 2007.

10. Standard SFS-EN 16798-1, 'Part 1: Indoor environmental input parameters for design and assessment of energy performance of buildings addressing indoor air quality, thermal environment, lighting and acoustics.', Finnish Standards Association SFS, Helsinki, Finland, 2019. 